\title{
Notas sobre el primum cognitum en Cayetano y su vínculo con la metafísica
}

\section{Notes about the primum cognitum in Cajetan and its link with metaphysics}

\author{
Ceferino MuÑZ \\ Universidad Nacional de Cuyo (Argentina)
}

Recibido: 16/05/2014

Aceptado: 18/09/2014

\section{Resumen}

Cayetano tuvo un papel protagónico en los debates intelectuales de su época (s. XVI), destacándose como un auténtico adalid del tomismo; inclusive muchas de sus tesis pasaron a formar parte de tal doctrina, las cuales - a veces matizadas y otras no tanto- perviven hasta nuestros días. Entre los diversos temas que afrontó se destaca su particular noción de primum cognitum. Aquí, partimos del hecho de que la tradición tomista no ha visto mayores inconvenientes en equiparar lo que entienden Cayetano y el Aquinate por el ens primo cadit; empero nosotros estamos en condiciones de afirmar que tal equiparación al menos es problemática. En este sentido, nos ocuparemos de realizar un primer acercamiento al tema del ente primer conocido cayetaniano para intentar mostrar su real significado. Asimismo, procuraremos ver, ayudados por los aportes de algunos estudiosos contemporáneos -en especial el de Lawrence Dewan-, hasta qué punto tal noción se corresponde o no con los desarrollos teóricos de Tomás de Aquino, sobre todo con el vínculo entre el primer conocido y el ente como objeto de la metafísica.

Palabras clave: Cayetano, ens primum cognitum, Lawrence Dewan, metafísica, Tomás de Aquino.

\section{Abstract}

Cajetan had the main role in the intellectual debates of his era (16 th century), being outlined as an authentic leader of thomism; indeed many of his theses became 
part of that doctrine, which -sometimes changed and sometimes not-remain in the present. Among the diverse topics that he confronted, it is very important his particular notion of primum cognitum. On this writing, we realize that the thomistic tradition has not seen major problems in comparing what Cajetan and Aquinas understand as ens primo cadit; however we can affirm that such comparison is problematic at least. In this sense, we will make an approach to the topic of the Cajetan's first being known to try to show its real meaning. Likewise, we will try to consider, helped by the contributions of some contemporary experts -especially Lawrence Dewan's-, if such notion corresponds or not with Thomas de Aquina's theoretical developments, especially with the link between the first being known and the being as object of the metaphysics.

Keywords: Cajetan, ens primum cognitum, Lawrence Dewan, metaphysics, Thomas Aquinas.

\section{La abstracción y sus clases}

Al hablar de abstracción dentro de la corriente tomista la referencia inmediata es la de Tomás de Vio y sus conocidos grados de abstracción formal1, ya sea para criticar esta doctrina o para rescatar alguno de sus postulados fundamentales a fin de conciliarla con la teoría de Santo Tomás. Puesto que nos proponemos aquí dilucidar qué entiende por ente el Cardenal, y en concreto por ens primum cognitum, será fundamental lograr una aproximación a dicha doctrina, ya que en cada uno de sus tipos de abstracción se obtiene un determinado tipo de ente.

Para él, existen tres tipos de abstracción:

[...] el ente puede ser término del acto del entendimiento bajo tres condiciones. Primero, en cuanto tiene la condición de la abstracción total, no de los singulares sino de las especies y de los géneros. Segundo, en cuanto tiene la condición de la abstracción formal, similarmente de las especies y de los géneros. Tercero, no teniendo ninguna de esas condiciones, y sin embargo abstraído de los singulares. Según el primer modo, el ente no es pertinente a esta cuestión, ya que el mismo como tal es un todo universal; ahora bien, nosotros hablamos del conocimiento confuso actual, no virtual. Conforme al segundo modo, el ente es un término que pertenece a la metafísica, y tal vez no ha sido advertido todavía por los más doctos. Según el tercer modo, el ente es lo primero conocido, y se designa como ente asociado a la quididad sensible porque no

\footnotetext{
1 Viene al caso recordar que Cayetano nunca utiliza la expresión grados de abstracción. Asimismo, el uso del término «grados» es problemático, pues habría grados si un modo superior consistiera en una intensificación del inferior, cosa que según Sanguineti no ocurre en el pensamiento del Cardenal. Cfr. J. J. Sanguineti. La filosofía de las ciencias según Santo Tomás. Pamplona, Eunsa, 1977, p. 188.
} 
está separado de la quididad específica o genérica según alguna de las abstracciones mencionadas. ${ }^{2}$

Entonces, para Cayetano, el ente puede ser objeto del entendimiento de tres modos diversos: con abstracción total, con abstracción formal y con abstracción de los singulares ${ }^{3}$. Con la primera - la total- se considera un todo, sin tener en cuenta los individuos en los cuales se realiza; es lógica y común a todas las ciencias y se constituye desde las especies y los géneros. Por ejemplo, se puede considerar una especie de animal (perro) sin considerar los individuos (los perros concretos, por ejemplo Brunelo); así la especie abstrae de los individuos. O se puede considerar el género (animal) sin considerar las especies (perro, gato, buey, etc.), o el género remoto (viviente) sin considerar el más próximo (animal, planta). Con ella se alcanza el concepto comunísimo y lógico de ente ${ }^{4}$, al que no hay que confundir -precisa Cayetano- con el ente como objeto de la metafísica.

La segunda abstracción es la formal, en la que están contenidos los tres modos de conocimiento objetivo. Es decir, aquella por la cual se obtienen los objetos de las ciencias teóricas (física, matemática y metafísica). Dicha abstracción considera lo formal, dejando lo que es material, toma lo actual dejando lo potencial y considera la forma abstrayéndola de la materia 5 . En este proceso de ir de lo más potencial a lo más actual, la abstracción va obteniendo inteligibles de un nivel cada vez más elevado.

En el tercer caso, con la abstracción de los singulares, el intelecto va de lo singular a lo universal. Aquí el ente es lo primero que se conoce; es el ens concretum quidditati sensibili, es decir, el ente asociado a la quididad sensible. Y ese no es el ente propio del saber metafísico, ya que éste se obtiene por la abstractio formalis, tal como se señaló.

En suma, por la abstracción total se llega al ente como un género generalísimo. Por la abstracción formal se alcanza el ente matemático, el físico y el metafísico,

\footnotetext{
2 " [...] ens sub triplici conditione potest terminare actum intellectus. Primo ut habet conditionem istam, quae est abstractio totalis, non dico a singularibus sed a speciebus et a generibus. Secundo modo ut habet conditionem istam quae est abstractio formalis similiter a speciebus et generibus. Tertio modo ut neutram istarum conditionum habens, abstractum tamen a singularibus. Primo modo ens non est pertinens ad hanc quaestionem, quia ipsum ut sic est totum universale, nos autem loquimur de cognitione confusa actuali non virtuali. Secundo modo ens est terminus metaphysicalis: et forte adhuc viris doctissimis non innotuit, Tertio modo ens est primum cognitum, et nuncupatum est ens concretum quiditati sensibili: quia non est separatum aliqua dictarum abstractionum a quiditate specifica vel generica”. Cayetano. Comentaria in De Ente et Essentia D. Thomae Aquinatis. Laurent, Hyancinthi (ed.), Roma, Marietti, 1934, p. 6. En adelante se hará referencia a esta obra como Comentaria in De Ente... ${ }^{3}$ Cfr. Cayetano. Comentaria in De Ente..., p. 6.

4 Cfr. Cayetano. Comentaria in De Ente..., p. 24.

5 Cfr. L. Vicente Burgoa. “¿Abstracción formal o separación? Desde Tomás de Aquino a Cayetano”, Estudios Filosóficos, 138, 1999, pp. 242-247.
} 
respectivamente. Por la abstracción de los singulares se llega al ente de las cosas materiales, el que cae primero bajo nuestra aprehensión intelectual y al que, según Cayetano, refiere el Aquinate en el De ente et essentia cuando afirma que el ente y la esencia son lo que primero concibe el intelecto 6 .

\section{La doctrina de la abstracción como respuesta a Duns Escoto}

Ahora bien, si rastreamos el origen de esta disquisición de Cayetano entre esos distintos modos de acceso al ente, debemos retrotraernos a su ilustre comentario al De ente et essentia de su maestro Tomás7 . Es allí donde el obispo de Gaeta formula la mencionada distinción, pero no como fruto del mismo texto tomasiano sino en respuesta a una objeción escotista. En realidad, las objeciones que plantea el Sutil son cinco, pero es en especial una la que obliga al Cardenal a responder con su notable ingenio. Así explica nuestro autor la objeción de Duns Scoto:

[...] los términos metafísicos universalísimos son actualmente los últimos conocidos por la vía de la doctrina. Ésta es patente desde que Avicena (I Metaph., cap. III) afirma que la metafísica es la última en el orden de las doctrinas. Pero aquellos términos son universalísimos: luego las más universales no son las primeras conocidas actualmente. Y se confirma, al decir de Antonio Trombeta, que el orden de las ciencias para nosotros se considera según el orden de lo más cognoscible para nosotros; si entonces la metafí-

\footnotetext{
${ }^{6}$ Cayetano. Comentaria in De Ente..., p. 1. Existen distintas posiciones con respecto a la operación intelectual que permitiría la captación del primum cognitum en el Aquinate. Un estudio más pormenorizado en relación con esto excedería ampliamente los límites de estas páginas. Con todo, puede bastar por el momento mencionar la posición de algunos de los tomistas más reconocidos: para Jacques Maritain, siguiendo la clasificación de Cayetano, el ente primer conocido se captaría por abstracción, cfr. J. Maritain, Breve trattato dell'esistenza e dell'esistente, Brescia, Morcelliana, 1984. Para Cornelio Fabro se lograría por una aprehensión sintética según el acto de ser, cfr. C. Fabro. "Problematica del Tomismo di Scuola", Rivista di Filosofia Neo-scolastica, 75, 1983, pp.187-199. Para Étienne Gilson en la captación de primer conocido, además de la simple aprehensión, el juicio tendría un papel fundamental al respecto, cfr. E. Gilson. El ser y los filósofos, Pamplona, Eunsa, 2005, pp. 247ss. Estudios más actuales como el de J. Aertsen, apartándose de la visión gilsoniana, concluyen que: "el ente se capta en una aprehensión simple. El concepto principalmente significa 'lo que tiene ser', 'lo que es', una frase que no lleva consigo un juicio". J. Aertsen. La filosofía medieval y los trascendentales. Un estudio sobre Tomás de Aquino. Colección de Pensamiento Medieval y Renacentista 52, Pamplona, Eunsa, 2003, p. 179.

7 Un tratamiento similar puede encontrarse en: B. Braun. Ontische Metaphysik. Zur Aktualität der Thomasdeutung Cajetans. Königshausen-Neumann, Würzburg, 1995, pp. 25ss; S. Gelonch. Separatio y Objeto de la Metafísica. Una interpretación textual del Super Boetium de Trinitate, q5 a3, de Tomás de Aquino. Pamplona, Eunsa, 2002, pp. 47 ss. y en B. Palla. "Aquinas on the Object of the Intellect", Proceedings of the Society for Medieval Logic and Metaphysics, 7, 2007, pp. 48-53.
} 
sica es la última para nosotros: luego su término será también el último conocido para nosotros. 8

El argumento del escocés está armado del siguiente modo: a- la metafísica tiene como objeto propio el ente, $b$ - la metafísica es la última de las ciencias conocidas por el intelecto humano (ya que llegamos a ella después de haber pasado por la física y la matemática), c- luego, el ente no puede ser lo primero captado por la inteligencia.

Esta es la objeción que le da motivo a Escoto para sostener que el primum cognitum es la species specialissima ${ }^{9}$. Ésta sería la última determinación por la cual, por ejemplo, este hombre es este hombre, lo más cercano desde el punto de vista inteligible al individuo: sea hombre, $\mathrm{u}$ hombre blanco, o Pedro. Esto es lo primero que se intelige -sostienen los escotistas- y no ente y esencia como dice Tomás de Aquino. Lo primero que yo conozco es lo inteligible pero de lo singular, lo que más se acerca a lo singular.

Cayetano, con su acostumbrada agudeza, resuelve el problema escotista arguyendo que uno es el ente objeto de la metafísica, el cual se obtiene por la abstratio formalis, y otro el ente como primum cognitum, el cual se halla concretado en la quididad sensible y es alcanzado por el tercer modo de abstracción, el correspondiente a la abstracción de los singulares ${ }^{10}$. A ojos vista, la objeción escotista queda brillantemente refutada, pero para lograrlo el comentador dominico no sólo ha tenido que aceptar parte del argumento de Escoto - uno es el ente de la metafísica y otro el ente captado primero-, marcando así una llamativa diferencia entre lo sensible y lo inteligible, sino que, además, ha elaborado para ello la ya mencionada doctrina de los modos objetivos de cognoscibilidad ${ }^{11}$.

\section{El primer conocido}

No sólo la división de las ciencias al modo cayetaniano ha pasado a formar parte de lo que se conoce como el sistema o la filosofía aristotélico-tomista, sino también

\footnotetext{
8 "Termini metaphysicales vel universalissimi sunt ultimo actualiter noti via doctrine. Patet ista ex Avicenna (2) (I Metaph., cap; in) dicente quod metaphysica est ultima ordine doctrinae, sed termini illi sunt universalissimi: ergo universaliora non sunt prius nota actualiter. Et confirmartur, ait Antonius Trombeta, quia ordo scientiarum quoad nos attenditur penes ordinem cognoscibilium quoad nos; si ergo metaphysica est ultima quoad nos: ergo termini sui erunt etiam ultimo noti quoad nos". Cayetano. Comentaria in De Ente..., pp. 4-5.

9 Cfr. Cayetano. Comentaria in De Ente..., pp. 4-5.

10 Cfr. Cayetano. Comentaria in De Ente..., pp. 4-5.

11 Hemos optado por esta terminología porque nos parece que plantea menos problemas interpretativos que la de grados de abstracción. La denominación «modos objetivos de cognoscibilidad» puede encontrarse en L. Vicente Burgoa. "Oggetto e obiettività. Le classificazioni degli oggetti del conoscere e il problema dell'oiecttività nel realismo classico", Divus Thomas, 102, 1999, p. 228.
} 
esta última distinción referida al primer conocido o ens quidditatis sensibili. La clasificación de las ciencias que plantea el Cardenal tuvo variadas y fuertes críticas desde mediados del siglo pasado, sobre todo desde la aparición del autógrafo de Tomás de Aquino titulado Expositio super Boethium de Trinitate, pues en dicho texto aparece la separatio (un juicio de separación negativa) como método de la metafísica ${ }^{12}$. Sin embargo, no ocurrió lo mismo con la segunda distinción -el ens quidditatis sensibili-, ya que los tomistas en general no tuvieron mayores inconvenientes en su comprensión, pues la identificaban sin más con el primo cadit de Santo Tomás. Con todo, aún en la actualidad, diversos estudiosos del pensamiento cayetaniano continúan con la tarea de elucidación del primer conocido del que nos habla el comentador de Gaeta. Al parecer, la labor no es nada sencilla, pues para filósofos como Bruno Pinchard tal noción no deja de ser en cierto sentido enigmática13. Lo es, a nuestro entender, porque este segundo grupo de pensadores se ha percatado de que Tomás de Vio no sólo tiene un lenguaje diverso del de Tomás de Aquino, sino que posee una metafísica propia que en varios puntos primordiales difiere de la de su maestro ${ }^{14}$. Entonces, desbrozar el terreno para no confundir lo que plantea cada fraile ya de por sí es una tarea difícil, dado que según la tradición lo que ha hecho el Cardenal es comentar fielmente al Aquinate ${ }^{15}$. Por otro lado, no podemos dejar de mencionar la complejidad del pensamiento cayetaniano que de por sí plantea un reto para nada minúsculo a quien quiera adentrarse en su metafísica.

Ahora bien, si tuviéramos que enunciar algunas notas que caracterizan al ens primero conocido, tal como lo entiende Cayetano, podríamos apuntar que:

i- Se obtiene por un particular tipo de abstracción llamada a particularibus o también neutra ${ }^{16}$.

ii- Es el concepto primero en el orden de originación (o quoad nos), y por ende el más imperfecto de todos ${ }^{17}$.

12 L. B. Geiger. "Abstraction et separation d'après s. Thomas. In de Trinitate q5 a3", Revue des Sciences Philosophiques et Theologiques, 31, 1947, p. 28. Éste fue uno de los primeros autores que abordó la cuestión a fondo. Una lista bastante completa del resto de los pensadores que también trataron el tema, puede verse a lo largo del libro de S. Gelonch, Separatio y objeto de la metafísica..., o.c. 13 B. Pinchard, Métaphysique et sémantique, autour de Cajétan, Paris, Vrin, 1987, p. 167.

14 Un tratamiento reciente de algunos de estos puntos pueden encontrarse en: C. Muñoz. "El ens en Cayetano: una aproximación a su significado e implicancias metafísicas", Trans/Form/Ação, 3/36, 2013, pp. 23-34. Del mismo autor: "Concepto formal y concepto objetivo en Cayetano. Un análisis a partir de su comentario al De ente et essentia”, Estudios Filosóficos, 179/62, 2013, pp. 49-61.

15 Incluso pensadores como Gilson, quienes se caracterizaron por una vigorosa crítica al Cardenal, tuvieron una inicial adhesión a su doctrina, viendo una correlación entre Tomás de Aquino y su comentador. Cfr. E. Gilson. Compagnons de route. En: E. Gilson, Philosophe de la Chrétienté, Paris, Cerf, 1949, p. 294.

16 Cfr. Cayetano. Comentaria in De Ente..., p. 6.

17 Cayetano. Comentaria in De Ente..., pp. 3-4. 
iii- Se logra por un conocimiento actual y confuso ${ }^{18}$ : actual porque el intelecto está actualmente concibiendo ente y confuso porque la inteligencia no distingue en el ente si es substancia o accidente.

iv- Significa lo mismo que el concepto de ente. Si bien la equiparación no aparece así de explícita en el comentario de Cayetano, algunos autores afirman que la misma es totalmente válida 19 .

v- En este sentido, el concepto de ente, según explica el Cardenal, es una cierta forma generalísima del entendimiento, así como la forma de corporeidad es forma generalísima de la materia misma 20.

vi- Otra nota que caracteriza a este ente concretado en lo sensible es que no deja de ser algo «distinto» de lo sensible mismo. Explica Cayetano en su opúsculo De conceptu entis: "[...] pues si el ente no puede desligarse de la naturaleza de las cosas, no será simplísimo, ni el primero conocido, ni término último de análisis, ni a lo que todo lo demás añaden"21.

vii- El ente primer conocido no se identifica ni con el ens trascendental22 ni con el ens metafísico 23.

En esta oportunidad nos interesa detenernos en la última distinción mencionada, pues la misma supone que cuando el ente no se apoya en alguno de los modos objetivos de cognoscibilidad que opera la inteligencia aún no hay ciencia o conocimiento distinto, sino tan sólo una captación común de lo sensible. En otras palabras, la ciencia se inicia con la abstracción formal; previo a esto sólo tenemos un conocimiento vulgar, empero ni ciencia ni captación de necesidades inteligibles 24 . De esto se desprende que el ente primero conocido poseería un status inferior y poco tendría que ver con las entidades que se obtienen por las abstracciones científicas, y menos aún con el ente metafísico que se logra en el mayor nivel de inmaterialidad abstractiva. Por ello, Jacques Maritain -que conoció muy bien la obra de Cayetano $25-$ afir-

18 Cayetano. Comentaria in De Ente..., p. 5.

19 Cfr. F. Riva. "Il Gaetano e 1'ente come «primum cognitum»", Rivista di Filosofia Neoescolastica, 85/1, 1993, p. 18.

20 Cfr. Cayetano. Comentaria in De Ente..., p. 11.

21 "[...] quandoquidem si ens absolvi non potest a naturis rerum, non erit simplicissimus; nec primo notus, nec in quem ultimo resolutio fiat, et ad quem omnes addunt". Cayetano. Acerca del Concepto de Ente. Texto latino según ed. Zammit, Trad. y notas de G. Soaje Ramos, Mendoza, Universidad Nacional de Cuyo, Instituto de Filosofía, 1949, p. 185.

22 Cfr. Cayetano. Comentaria in De Ente., p. 88.

23 Cfr. Cayetano. Comentaria in De Ente..., p. 6.

24 Cfr. J. Maritain. La filosofía de la naturaleza. Trad. J. R. Delgado, Buenos Aires, Club de Lectores, 1980, p. 35.

25 Cfr. M. A. Vitoria. Las relaciones entre filosofia y ciencias en la obra de J. Maritain. Roma, Edizioni Università della Santa Croce, 2003. J. Álvarez Álvarez, "Apuntes para una teoría del saber: la prospectiva de Jacques Maritain", Arbor Ciencia, Pensamiento y Cultura, 183, 2007, pp. 567-579. J. L. Illanes. "Características del filosofar. Análisis del testimonio de Jacques Maritain”, Anuario Filosófico, 9/1, 1976, pp. 193-245. 
ma que el ente primum cognitum nunca podría identificarse con el objeto de la ciencia primera, pues si así sucediera cualquier persona, incluso un niño, sería ya un metafísico o, dicho de otro modo, contactaría inmediatamente con el objeto de la metafísica ${ }^{26}$. Basta consultar algún manual de filosofía tomista para comprobar que la distinción mentada por el Cardenal ha pasado al acervo de la tradición; incluso en autores que han revisado muchos puntos de la doctrina tomista, y que han intentado depurarla de lo que se suponía no era enseñanza de Tomás sino de sus comentadores, aceptan esta división entre el primer conocido y el ens metafísico 27.

\section{El enfoque de Lawrence Dewan}

Pero continuemos nuestra indagación sobre esta última división, ya que, según otros estudiosos, la misma no estaría presente en el pensamiento aquiniano. Ahora bien, si lo que pretende Cayetano es explicar y defender la doctrina de Tomás de Aquino, entonces nos encontraríamos ante un inconveniente palmario que será necesario intentar aclarar para ver si la distinción de marras es propia del comentador italiano.

Ya en su momento, autores como Fabro 28 , Gilson ${ }^{29}$ y Owens ${ }^{30}$ advirtieron -aunque sin tematizar mucho al respecto- que la división cayetaniana entre el primer conocido y el ente como objeto de la metafísica no se encontraba en la letra de Tomás. Con todo, se nos podría objetar que este grupo de pensadores se caracterizó por un férreo anticayetanismo ${ }^{31}$, por lo que posiblemente hayan visto por doquier

26 Cfr. J. Maritain. Siete lecciones sobre el ser. Trad. J. González, Buenos Aires, Dedebec, Ediciones Desclée de Brouwer, 1943, p. 37.

27 Citamos tres casos: R. Schmidt. "L'emploi de la séparation en métaphysique", Revue Philosophique de Louvain, 58/59, 1960, p. 381; L. Elders, Faith and Science. An introduction to St. Thomas 'Expositio in Boethii De Trinitate, Herder, Roma 1974, p. 108; Tomás de Aquino. El ente y la esencia. Trad., estudio preliminar y notas de E. Forment, Pamplona, Eunsa, 2006, p. 64. La página corresponde al estudio preliminar que realiza Forment. Con respecto a la postura de Elders, la misma podría matizarse si se tiene en cuenta que en un escrito posterior afirma que no es el mismo el ente primer conocido y el de la metafísica porque el objeto de esta ciencia es el esse. Cfr. L. Elders. "La naturaleza de la metafísica según San Alberto Magno y Santo Tomás de Aquino", Scripta Theologica, 122, 1980, p. 559.

28 Cfr. C. Fabro. Percepción y pensamiento. Pamplona, Eunsa, 1978, p. 589. Un exhaustivo rastreo de los lugares en los cuales Fabro aborda el tema del ente como primer conocido puede verse en: L. Romera Oñate. El primado noético del «ens» como primum cognitum. Análisis de la posición de Cornelio Fabro. Pamplona, Servicio de Publicaciones de la Universidad de Navarra, 1991.

${ }^{29}$ Cfr. E. Gilson. El Tomismo: introducción a la filosofia de Santo Tomas de Aquino. Eunsa, Pamplona, 2002, p. 193.

30 Cfr. J. Owens. The Doctrine of Being in the Aristotelian Metaphysics: A Study in the Greek Background of Mediaeval Thought. Toronto, Pontifical Institute of Mediaeval Studies, 1978, p. 295.

31 Cfr. S. T. Bonino. "La historiografía de la escuela tomista: el caso Gilson", Scripta Theologica 26, 1994/3, pp. 955-976. 
infidelidades doctrinales del Cardenal a su maestro. Si bien estamos persuadidos de que éste no fue el caso, y que sus críticas - por lo menos en los puntos que conocemos- fueron justificadas, aun así preferimos traer aquí la opinión de un segundo grupo de estudiosos que también han observado discrepancias importantes en este punto. Nos referimos a Caldera ${ }^{32}$, Pascual ${ }^{33}$ y Dewan ${ }^{34}$; pensadores todos que ejercen actualmente su labor investigativa en diferentes ámbitos académicos del mundo. Sin embargo, y con el objeto de restringir aún más las posibles aversiones y/o imparcialidades hacia la exégesis de Cayetano, en lo que sigue nos centraremos en lo que ha dicho Lawrence Dewan. Este autor se encuentra libre de sospechas de antipatías hacia Tomás de Vio; incluso ha defendido al Cardenal de las críticas que algunos medievalistas le realizaron 35 .

Tal como destaca Stephen Brock, el dominico Lawrence Dewan ha tenido una posición sumamente destacada entre los estudiosos de Tomás de Aquino, sobre todo en Norteamérica; esto a pesar de la falta de circulación apropiada de sus numerosos e importantes escritos ${ }^{36}$. Precisamente en una de sus últimas obras, Form and Being. Studies in Thomistic Metaphysics, sostiene la tesis de que el ente primero conocido es el mismo que el del objeto del saber metafísico ${ }^{37}$. En el tercer capítulo de dicho volumen, a partir de la doctrina tomasiana de las virtudes y haciendo especial referencia a las intelectuales (la ciencia y la sabiduría), el profesor canadiense despliega su argumentación como sigue: las virtudes se obtienen por la repetición de actos, y el agente que obra tiene en sí una serie de principios activos y pasivos. El principio activo no es perfectible por la operación del agente, y esto se debe a la gran nobleza de tal principio, pues por ello afirma Tomás en la Suma de Teología que la comprensión de los principios es más noble que la ciencia de las conclusio-

32 Cfr. R. Caldera. La primera captación intelectual. Pamplona, Cuadernos de Anuario Filosófico, 1999 , p. 36.

33 Cfr. R. Pascual. La división de las ciencias especulativas en santo Tomás de Aquino. Roma, Facultate Philosophiae Pontificiae Universitatis Gregorianae, 2003, p. 95.

34 Cfr. L. Dewan. Form and Being. Studies in Thomistic Metaphysics, The Catholic University of America Press, vol. 45, Washington 2006. . En adelante se hará referencia a esta obra como Form and Being...

35 Cfr. L. Dewan. "Etienne Gilson and the Actus Essendi". International Journal of Philosophy, 1, 2002, pp. 65-99. También del mismo autor: Aristotle as a Source of St. Thomas's Doctrine of esse. Maritain Center, University of Notre Dame, Thomistic Institute for the year 2000. (En línea: www3.nd.edu/Departments/Maritain/ti00/dewan.htm). Ver sobre todo el apartado titulado The 20th Century Problem of Aristotle as Source (Gilson).

36 Cfr. S. Brock. "Lawrence Dewan, O.P., Form and Being. Studies in Thomistic Metaphysics", Acta Philosophica, 17/1, 2008, p. 189 (Recenzioni).

37 Cfr. L. Dewan. Form and Being..., pp. 35-60. Este capítulo apareció originalmente en L. Dewan, St. Thomas and the Ground of Metaphysics. In: J. B. Brough, D. O. Dahlstrom, and H. B. Veatch (eds.), Philosophical Knowledge. Washington, Proceedings of the American Catholic Philosophical Association, vol. 54, 1980, pp. 144-154. 
nes 38 . Como principio activo el Aquinate hace referencia a la proposición per se notam. En esta dirección, si ens es conocido con prioridad a los prima principia, luego tendrá una nobleza que es anterior al conocimiento de los mismos, pues el status del primer ente inteligido será también el de semilla de la sabiduría. Los primeros principios también son scientias seminas, pues junto con el ente son las primeras concepciones que aprehende el intelecto ${ }^{39}$; pero el ente es una primera concepción incompleja y los primeros principios son concepciones complejas ${ }^{40}$.

En el mismo capítulo tres de Form and Being, Dewan inicia la exposición de otro de los argumentos que exaltan la dignidad del primer conocido. A saber, el ente incluye el ser en su significado; más aún, un ente no es su propio ser, sino que es un ens por participación ${ }^{41}$. En este sentido, en el capítulo cuarto de la misma obra, el autor muestra que en la noción de ente ya está presente un conocimiento confuso de esse, debido a la proporción que existe entre el ens y el esse. Y es precisamente este carácter de ens el que hace las veces de punto de partida de la metafísica 42 .

El último de los argumentos que expone el dominico canadiense en pos de la nobleza del primer conocido aparece en el mismo capítulo cuatro de Form and Being ${ }^{43}$. Allí retoma en parte lo que ya había dicho respecto a que el ente como primer conocido es un principio activo que no está sujeto a perfección por la operación del agente. Por el contrario, este ente es la fuerza vital para el entero desarrollo de la vida intelectual 44 , y concierne propiamente a la metafísica. Dewan lo dice claramente: "el ente que pertenece a la metafísica es el ente que nosotros conocemos como la misma fuente de toda operación intelectual" 45 . Lo que el fraile canadiense está queriendo expresar es que el ente primero conocido es una luz perfecta que se irá revelando en nuestros esfuerzos intelectuales, tendiendo en sus movimientos hacia el conocimiento de Dios, es decir, del ipsum esse subsistens. Por ello, según Dewan -contradiciendo lo que había sostenido Maritain-, somos proto-metafísicos desde el inicio de nuestra vida intelectual, es decir, mucho antes de que nos hagamos científicos de la metafísica 46 .

38 Cfr. Tomás de Aquino, S.Th. I-II, q. 51 a. 2 ad 3.

39 Cfr L. Dewan. Form and Being..., pp. 36-38.

40 Cfr. Tomás de Aquino. De Verit., 11, 1, c.

41 Cfr. L. Dewan. Form and Being..., p. 43.

42 Cfr. L. Dewan. Form and Being..., p. 46.

43 Cfr. L. Dewan. Form and Being..., pp. 47-60. Capítulo aparecido originalmente en: L. Dewan. "St. Thomas, Physics, and the Principle of Metaphysics", The Thomist, 61, 1997, pp. 549-566.

44 Tomás Melendo se expresa en términos similares: "[...] el primum cognitum se constituye en fundamento último de la dilatación y engrandecimiento de toda la vida intelectual". T. Melendo, Esbozo de una metafisica de la belleza, Cuadernos de Anuario Filosófico n 96, Eunsa, Pamplona, 2000, p. 28.

45 Cfr. L. Dewan. Form and Being..., p. 60.

46 Cfr. L. Dewan. Form and Being..., p. 60. Una confutación que se nos podría hacer es que no hemos considerado que la diferencia que establece Cayetano entre el ente primer captado y el objeto de la 


\section{Consideraciones finales}

Lo que hemos intentado en este recorrido fue, primero, un acercamiento a la noción del ente primer captado de Cayetano y, segundo, ver, mediante el enfoque de uno de los más importantes representantes actuales del tomismo, el dominico canadiense Lawrence Dewan, por qué tal noción no convendría con la doctrina tomasiana, toda vez que intenta desligarse de su relación con la ciencia metafísica.

Con respecto a lo primero, por las características descriptas, el ens cayetaniano parecería aproximarse en mayor medida al plano conceptual que al real, contrariamente a lo que podrían indicar las palabras que usa el de Gaeta: ens concretum quidditatis sensibilis. Incluso en algunos estudiosos actuales tal terminología ha dado lugar a confundir el ens primo cadit de Tomás de Vio con otra noción que también emplea el autor: la de esse actualis existentiae ${ }^{47}$, la cual señalaría la realidad fáctica o extramental de un ente 48 . Sin embargo, por las características que hemos esbozado, se corresponde con el conceptus entis.

En razón de esto, lo primero que se conoce para Cayetano es un concepto; es verdad que será del ente, pero no deja de ser un concepto. La preponderancia es lógica y no real, ya que aquel ente del que nos hablaba Tomás y que cae primero en el intelecto, para el comentador italiano será una segunda intención. Por ello, Pinchard cree que desde la visión cayetaniana las categorías se deducirían del concepto de ente 49 . Al respecto y en la misma línea hermenéutica, en un reciente escrito, afirma Leo Elders:

\footnotetext{
metafísica podría corresponder con aquella distinción que se da entre el objeto terminativo o en cuanto cosa (ut est res), también llamado objeto formal quod, y el objeto motivo en cuanto escible o cognoscible (ut est scibile) u objeto formal quo. Cfr. Tomás de Aquino. Suma de Teología. Madrid, B.A.C, t. I, 2001, p. 88. La explicación pertenece al prólogo de Fray Alberto Escallada Tijero O.P. Dichas clasificaciones, aunque varíen en sus nombres, han sido utilizadas por los más encumbrados comentadores del Aquinate. Esto es verdadero, ahora bien, si se rastrean en la letra aquiniana, difícilmente asomen, por lo menos así expresadas y concatenadas conceptualmente como aparecen especialmente en las obras de los comentadores. En un extenso y valiosísimo artículo, Pier Paolo Ruffinengo sintetiza el pensamiento de varios de los representantes de la escuela tomista en torno al objeto de la metafísica. Por lo que plantea Ruffinengo, las divisiones de los comentadores son propias de ellos y no de Tomás. Es cierto que recogen una que otra afirmación de la obra de éste, y a partir de ella desarrollan e incorporan distinciones notables pero que nunca aparecen en la obra tomasiana. Cfr. P. P. Ruffinengo. "L'oggetto della metafisica nella scuola tomista tra tardo medioevo ed eta moderna", Medioevo: Rivista di storia della filosofia medievale 34, 2009, pp. 141-219.

47 Cfr. C. Blackwell. "Thomas Aquinas against the Scotists and Platonists: The definition of ens: Cajetano, Zimara, Pererio, 1495-1576”, Verbum, 6, 2004, p. 183.

48 A. L. González. Ser y Participación: Estudio sobre la cuarta vía de Tomás de Aquino. Pamplona, Eunsa, 2001, p. 116. También: J. J. Herrera. La simplicidad divina según Santo Tomás de Aquino. San Miguel de Tucumán, UNSTA, 2011, p. 457.
}

49 B. Pinchard. Métaphysique et sémantique..., o.c. p. 168. 
Cayetano procede con un modo de pensamiento lógico, como si nosotros formásemos el concepto de ente desprendiéndolo de las categorías, para preguntarnos luego lo que resulta. En la metafísica se observan las cosas existentes, las sustancias y los modos de ser real, ya no como subsistentes por sí, sino en otro. Se extiende así el concepto de ser real a estas formas. Sin embargo, entiendo, que no se ha de considerar el concepto de ente como una realidad por sí, como lo hace Cayetano. Cayetano parece no haber valorizado bien la doctrina de que la sustancia es causa de los accidentes. 50

Lo que sucede es que el medio o aquello a través de lo cual se da el conocimiento (quo), se ha transformado en término del conocimiento (quod) 51 . Ahora parece entenderse más claramente por qué nuestro autor hablaba del concepto de ente como una forma generalísima o cuasi natural al entendimiento, comparándolo con el sustantivo abstracto «corporeidad», en cuanto forma generalísima de la materia ${ }^{52}$.

En esta dirección, nuestras afirmaciones también se ven refrendadas por Franco Riva ${ }^{53}$, quien incluso cree que el planteo de Cayetano cuando trata de esta cuestión capital es principalmente gnoseológico ${ }^{54}$, siendo que el mismo debería orbitar en torno a la filosofía primera 55 , pues se trata de dilucidar «qué es» lo primero conocido por el hombre, en virtud de lo cual el asunto no debería centrarse en lo «en tanto que conocido» sino en lo «en tanto que es», es decir, en su causa a través de un ordenamiento científico de la creación 56.

\footnotetext{
50 L. Elders. Cayetano, comentador de la Suma de teología de Santo Tomás [en línea], en: Semana Tomista. Intérpretes del pensamiento de Santo Tomás, XXXVI, 5-9 septiembre 2011. Sociedad Tomista Argentina; Universidad Católica Argentina. Facultad de Filosofía y Letras, Buenos Aires. (Disponible en: http://bibliotecadigital.uca.edu.ar/repositorio/ponencias/cayetano-comentador-sumateologia-tomas.pdf). Los resaltados pertenecen al autor.

51 El problema surge "cuando los conceptos, en lugar de hacerse a imagen de la realidad, comienzan a hacer la realidad a su propia imagen, [entonces] hay algo que no marcha bien en el reino de la metafísica”. E. Gilson. El ser y los filósofos, Pamplona, Eunsa, 2005, p. 134.

52 "[...] eo quod conceptus entis est quaedam forma generalissima ipsius intellectus, sicut forma corporeitatis est forma generalissima ipsius materiae". Cayetano. Comentaria in De Ente..., p. 11.

53 Cfr. F. Riva. "Il Gaetano e 1'ente...", o.c., p. 12. Incluso Bernard Besnier se pregunta si el primer conocido de Cayetano no sería una suerte de sucedáneo de la esencia neutra escotista. Cfr. Besnier, B. "Cajétan-In 'De Ente et Essentia' quaestio I". In: Pinchard, B. and Ricci, S. (eds.), Rationalisme analogique et humanisme théologique: la culture de Thomas de Vio 'Il Gaetano', Napoles 1993, pp. 82-83. 54 Cfr. F. Riva. "Il Gaetano e l'ente...", o.c., pp. 18-20. De la misma opinión es José Mendoza, quien incluso hace extensible la afirmación a toda la metafísica del Cardenal: "[...] la metafísica de Tomás de Vio Cayetano pareciera colocar el acento en un estudio de la naturaleza esencialmente lógico-gnoseológico". J. M. Mendoza. "La Epistemología tomista: un desvío de la originaria noción tomística de ciencia", Ciencia Tomista, 140/3, 2013, p. 395.

55 Cfr. J. Rassam. La métaphysique de Saint Thomas. Paris, PUF, 1968, p. 1. El mismo Tomás sostiene que la filosofía primera se ocupa de la causa primera de las cosas, a saber: su esse. Cfr. Tomás de Aquino, In Metaphys. pr., n. 9; Super De Trinitate, pars 3 q. 6 a. 1 co. 22.

56 Cfr. J. M. Mendoza. "Aproximación a una misma ciencia de tres nombres: Methaphysica, Philosophia Prima y Theologia en el comentario de Tomás de Aquino al De Trinitate boeciano", Estudios Filosóficos, 179, 2013, p. 108.
} 
Podría objetarse que la noción del primer conocido o del concepto de ente que propone Cayetano no es más que una salida circunstancial a las confutaciones de Duns Scoto y de su discípulo Antonio Trombeta ${ }^{57}$. Sin embargo, creemos que es un núcleo temático que atraviesa todo el pensamiento metafísico del Cardenal. Incluso, según la mirada de uno de los estudiosos más reconocidos del pensamiento cayetaniano, Bruno Pinchard, aquí radicaría la gran distancia entre Tomás de Aquino y Cayetano. Mientras que la del primero sería una doctrina del acto de ser, la del segundo sería una doctrina del concepto de ente 58 .

Con respecto a lo segundo, el enfoque de Dewan, no hemos encontrado que el autor amoneste explícitamente a Cayetano sobre este asunto. Es decir, cuando el fraile canadiense asevera con diversas razones que el primer captado y el objeto de la metafísica se identifican, no está criticando explícitamente a Tomás de Vio, pero al refutar tal tesis inexorablemente se aleja del comentador de Gaeta y de muchos tomistas que aún hoy afirman dicha escisión como verdadera y propia de la mentis aquiniana. Aquí sólo hemos visto sumariamente por qué motivos no habría distinción entre el primum cognitum y el objeto del saber metafísico en la doctrina tomasiana -por lo menos así como los distingue el Cardenal. Ahora bien, las consecuencias que se derivan de separarlos efectivamente creemos que son diversas y para nada de poca monta, razón por la cual sería conveniente estudiarlas más profundamente.

\section{Referencias bibliográficas}

AERTSEn, J. La filosofía medieval y los trascendentales. Un estudio sobre Tomás de Aquino. Colección de Pensamiento Medieval y Renacentista 52, Pamplona, Eunsa, 2003, p. 179.

Álvarez Álvarez, J. "Apuntes para una teoría del saber: la prospectiva de Jacques Maritain", Arbor Ciencia, Pensamiento y Cultura, 183, 2007, pp. 567-579.

Besnier, B. "Cajétan-In 'De Ente et Essentia' quaestio I". In: Pinchard, B. and Ricci, S. (eds.), Rationalisme analogique et humanisme théologique: la culture de Thomas de Vio 'Il Gaetano', Napoles 1993, pp. 71-83.

Beuchot, M. "Escoto y Ockham, negadores de la distinción real esencia-existencia: la lucha interna entre el escotista Trombetta y el tomista Cayetano", Cuadernos salmantinos de filosofía, 22, 1995, pp. 175-182.

\footnotetext{
57 Debe recordarse que Antonio Trombeta fue con quien el Cardenal mantuvo una larga polémica durante su enseñanza en Padua. De la misma surgen sus comentarios al De ente et essentia de Tomás de Aquino. Sirva como ejemplo de la polémica el trabajo de M. Beuchot. "Escoto y Ockham, negadores de la distinción real esencia-existencia: la lucha interna entre el escotista Trombetta y el tomista Cayetano", Cuadernos salmantinos de filosofia, 22, 1995, pp. 175-182.

58 B. Pinchard. Métaphysique et sémantique..., o.c., p. 168.
} 
Blackwell, C., "Thomas Aquinas against the Scotists and Platonists: The definition of ens: Cajetano, Zimara, Pererio, 1495-1576", Verbum, 6, 2004, pp. 179188.

Bonino, S. T. "La historiografía de la escuela tomista: el caso Gilson", Scripta Theologica 26, 1994/3, pp. 955-976.

Braun, B. Ontische Metaphysik. Zur Aktualität der Thomasdeutung Cajetans. Königshausen-Neumann, Würzburg, 1995.

Brock, S. "Lawrence Dewan, O.P., Form and Being. Studies in Thomistic Metaphysics", Acta Philosophica, 17/1, 2008, pp. 189-192.

BusA, R. (auctore). Thomae Aquinatis Opera Omnia: cum hypertextibus in CDROM. Milano: Editoria Elettronica Editel, 1992.

CALDERA, R. La primera captación intelectual. Pamplona, Cuadernos de Anuario Filosófico, 1999.

Cayetano. Acerca del Concepto de Ente. Texto latino según ed. Zammit, Trad. y notas de G. Soaje Ramos, Mendoza, Universidad Nacional de Cuyo, Instituto de Filosofía, 1949.

Cayetano. Comentaria in De Ente et Essentia D. Thomae Aquinatis. Laurent, Hyancinthi (ed.), Roma, Marietti, 1934.

Dewan, L. "St. Thomas, Physics, and the Principle of Metaphysics", The Thomist, 61, 1997, pp. 549-566.

Dewan, L. Form and Being. Studies in Thomistic Metaphysics, The Catholic University of America Press, vol. 45, Washington 2006.

Dewan, L. St. Thomas and the Ground of Metaphysics. In: J. B. Brough, D. O. Dahlstrom, and H. B. Veatch (eds.), Philosophical Knowledge. Washington, Proceedings of the American Catholic Philosophical Association, vol. 54, 1980, pp. 144-154.

Dewan, L. "Etienne Gilson and the Actus Essendi". International Journal of Philosophy, 1, 2002, pp. 65-99. Aristotle as a Source of St. Thomas's Doctrine of esse. Maritain Center, University of Notre Dame, Thomistic Institute for the year 2000. (En línea: www3.nd.edu/Departments/Maritain/ti00/dewan.htm).

Elders, L. Cayetano, comentador de la Suma de teología de Santo Tomás [en línea], en: Semana Tomista. Intérpretes del pensamiento de Santo Tomás, XXXVI, 5-9 septiembre 2011. Sociedad Tomista Argentina; Universidad Católica Argentina. Facultad de Filosofía y Letras, Buenos Aires. (Disponible en: http://bibliotecadigital.uca.edu.ar/repositorio/ponencias/cayetano-comentador-suma-teologia-tomas.pdf).

ELDERS, L. Faith and Science. An introduction to St. Thomas'Expositio in Boethii De Trinitate, Herder, Roma 1974.

ELDERS, L. "La naturaleza de la metafísica según San Alberto Magno y Santo Tomás de Aquino", Scripta Theologica, 122, 1980, p. 547-562. 
Fabro, C. "Problematica del Tomismo di Scuola", Rivista di Filosofia Neo-scolastica, 75, 1983, pp.187-199.

FABRo, C. Percepción y pensamiento. Pamplona, Eunsa, 1978.

Geiger, L. B. "Abstraction et separation d'après s. Thomas. In de Trinitate q5 a3", Revue des Sciences Philosophiques et Theologiques, 31, 1947, pp. 3-40.

Gelonch, S. Separatio y Objeto de la Metafísica. Una interpretación textual del Super Boetium de Trinitate, q5 a3, de Tomás de Aquino. Pamplona, Eunsa, 2002.

Gilson, E. Compagnons de route. En: E. GiLson, Philosophe de la Chrétienté, Paris, Cerf, 1949.

GILsON, E. El ser y los filósofos, Pamplona, Eunsa, 2005.

Gilson, E. El Tomismo: introducción a la filosofía de Santo Tomas de Aquino. Eunsa, Pamplona, 2002.

GonzÁlez, A. L. Ser y Participación: Estudio sobre la cuarta vía de Tomás de Aquino. Pamplona, Eunsa, 2001.

Herrera, J.J. La simplicidad divina según Santo Tomás de Aquino. San Miguel de Tucumán, UNSTA, 2011.

Illanes, J. L. "Características del filosofar. Análisis del testimonio de Jacques Maritain", Anuario Filosófico, 9/1, 1976, pp. 193-245.

MARITAIN, J. Breve trattato dell'esistenza e dell'esistente, Brescia, Morcelliana, 1984.

Maritain, J. La filosofía de la naturaleza. Trad. J. R. Delgado, Buenos Aires, Club de Lectores, 1980.

Maritain, J. Siete lecciones sobre el ser. Trad. J. GonZÁlez, Buenos Aires, Dedebec, Ediciones Desclée de Brouwer, 1943.

Melendo, T. Esbozo de una metafisica de la belleza, Cuadernos de Anuario Filosófico n 96, Eunsa, Pamplona, 2000, p. 28.

MendozA, J. M. "La Epistemología tomista: un desvío de la originaria noción tomística de ciencia", Ciencia Tomista, 140/3, 2013, p. 389-416.

MendozA, J. M. "Aproximación a una misma ciencia de tres nombres: Methaphysica, Philosophia Prima y Theologia en el comentario de Tomás de Aquino al De Trinitate boeciano", Estudios Filosóficos, 179, 2013, pp. 99-114.

MuÑoz, C. "El ens en Cayetano: una aproximación a su significado e implicancias metafísicas", Trans/Form/Ação, 3/36, 2013, pp. 23-34.

"Concepto formal y concepto objetivo en Cayetano. Un análisis a partir de su comentario al De ente et essentia”, Estudios Filosóficos, 179/62, 2013, pp. 4961.

Owens, J. The Doctrine of Being in the Aristotelian Metaphysics: A Study in the Greek Background of Mediaeval Thought. Toronto, Pontifical Institute of Mediaeval Studies, 1978. 
Palla, B. "Aquinas on the Object of the Intellect", Proceedings of the Society for Medieval Logic and Metaphysics, 7, 2007, pp. 43-53.

Pascual, R. La división de las ciencias especulativas en santo Tomás de Aquino. Roma, Facultate Philosophiae Pontificiae Universitatis Gregorianae, 2003.

Pinchard, B., Métaphysique et sémantique, autour de Cajétan, Paris, Vrin, 1987.

Rassam, J. La métaphysique de Saint Thomas. Paris, PUF, 1968.

Riva, F. "Il Gaetano e 1'ente come «primum cognitum»", Rivista di Filosofia Neoescolastica, 85/1, 1993, p. 3-20.

Romera Oñate, L. El primado noético del «ens» como primum cognitum. Análisis de la posición de Cornelio Fabro. Pamplona, Servicio de Publicaciones de la Universidad de Navarra, 1991.

Ruffinengo, P. P. "L'oggetto della metafisica nella scuola tomista tra tardo medioevo ed eta moderna", Medioevo: Rivista di storia della filosofia medievale 34, 2009, pp. 141-219.

Sanguineti, J. J. La filosofía de las ciencias según Santo Tomás. Pamplona, Eunsa, 1977, p. 188.

SCHMIDT, R. "L'emploi de la séparation en métaphysique", Revue Philosophique de Louvain, 58/59, 1960, pp. 373-393.

TomÁs de Aquino. El ente y la esencia. Trad., estudio preliminar y notas de E. Forment, Pamplona, Eunsa, 2006.

Suma de Teología. Madrid, B.A.C, T. I, 2001.

Vicente Burgoa, L. “¿Abstracción formal o separación? Desde Tomás de Aquino a Cayetano", Estudios Filosóficos, 138, 1999, pp. 211-256.

Vicente BurgoA, L. "Oggetto e obiettività. Le classificazioni degli oggetti del conoscere e il problema dell'oiecttività nel realismo classico", Divus Thomas, 102, 1999, p. 199-245.

Vitoria, M. A. Las relaciones entre filosofía y ciencias en la obra de J. Maritain. Roma, Edizioni Università della Santa Croce, 2003.

Ceferino Muñoz

Universidad Nacional de Cuyo (Argentina)

ceferinomm@hotmail.com 